\title{
A 12-MONTH EXERCISE INTERVENTION DECREASED STRESS SYMPTOMS AND INCREASED MENTAL RESOURCES AMONG WORKING ADULTS - RESULTS PERCEIVED AFTER A 12-MONTH FOLLOW-UP
}

\section{OILI KETTUNEN ${ }^{1,2}$, TIMO VUORIMAA ${ }^{3}$, and TOMMI VASANKARI ${ }^{4,5}$}

${ }^{1}$ University of Turku, Turku, Finland

Department of Health and Exercise \& Paavo Nurmi Center

${ }^{2}$ Sports Institute of Finland, Vierumäki, Finland

Department of Health and Exercise

${ }^{3}$ Haaga-Helia the University of Applied Sciences, Vierumäki, Finland

Department of Sports and Exercise

${ }^{4}$ UKK Institute for Health Promotion Research, Tampere, Finland

Department of Health Research

${ }^{5}$ National Institute for Health and Welfare, Helsinki, Finland

Department of Health Research

\begin{abstract}
Objectives: This study evaluated the effect of a 12-month physical exercise intervention accompanied by a 12-month followup evaluating stress symptoms (SS), mental resources (MR) and cardiorespiratory fitness (CRF) in healthy, working adults. We hypothesized that the stress symptoms would decrease and mental resources would increase during the intervention and that these results are associated with changes in CRF. Material and Methods: The study group included healthy adults $(\mathrm{N}=371)$. Three hundred thirty eight participants (212 women, $126 \mathrm{men})$ were allocated in the exercise group and 33 in the control group (17 women and 16 men). For the analysis, the exercise group was divided into subgroups according to the baseline SS and MR. Stress symptoms and MR were measured using the Occupational Stress Questionnaire. Results: During the 12-month exercise intervention, SS decreased by 16\% ( $<<0.0001)$, MR increased by $8 \%(\mathrm{p}<0.0001)$ and CRF increased by $7 \%(\mathrm{p}<0.0001)$ in the exercise group, while no changes occurred in the control group (ANCOVA, $p<0.01$ ). In the exercise group, the results (SS, MR, and CRF) remained improved during the follow-up. There was a positive correlation between the change in SS and the change in CRF $(r=0.19, \mathrm{p}<0.01)$. In the subgroup having the highest SS at baseline, SS during the intervention decreased most (26\%) (ANCOVA, $p<0.0001)$. Conclusions: One year physical exercise intervention improved mental well-being among working adults and this was associated with an improvement in cardiorespiratory fitness. The positive changes remained after the 12-month follow-up.
\end{abstract}

Key words:

Stress, Exercise, Cardiorespiratory fitness, Leisure time physical activity, Mental resources, Working adults

Received: June 16, 2014. Accepted: August 8, 2014.

Corresponding author: O. Kettunen, Sports Institute of Finland, Department of Health and Exercise, 19120 Vierumäki, Finland (e-mail: oili.kettunen@vierumaki.fi). 


\section{INTRODUCTION}

Physical activity is associated with increased well-being $[1,2]$. Physical activity can modify response to psychological stressors [3-6]. An association between emotional well-being and regular physical activity exists and is evident in people who exercise regularly [2,7]. Several studies report that depressive symptoms decrease with increased exercise [8-12]. Exercise that one enjoys decreases stress symptoms and depression and raises emotional well-being [13]. Recent studies investigating psychological well-being suggest that a high level of cardiorespiratory fitness (CRF) is associated with better psychological wellbeing $[14,15]$, but direct evidence for this remains inconclusive. Simultaneous investigations into the relationship of both self-reported physical activity and cardiorespiratory fitness with mental health is also unsettled [16].

Occupational health research has directed more attention towards the role of employee well-being in individual and organizational outcomes [17]. Work and employment play an important role in relation to mental health [18], and poor mental health constitutes a great threat to employees' ability to work [19]. Coping methods to recover from demanding work periods are important to protect workers' health and long term well-being [20]. Leisure activities that offer the opportunity to recover from job stress and to restore one's resources are important for maintaining one's well-being [21]. The conservation of resources (COR) theory [19] offers a theoretical perspective about the recovery from job stress. It serves as a general model on stress, health and well-being. Resources are objects, personal characteristics and energies that are either valued for survival, directly or indirectly, or serve as means of achieving these resources [22]. If an individual's resources are lost or if no resources are gained after resources have been invested, stress will occur and well-being will suffer [20].

The aim of this study was to investigate the effect of a 12-month exercise-training program with a moderate volume and a low intensity on stress symptoms, mental resources and cardiorespiratory fitness of healthy, working adults. Stress symptoms and mental resources were measured using the Occupational Stress Questionnaire (OSQ). The stability of the results was evaluated after a 12-month follow-up. We hypothesized that exercise intervention, which results in increased cardiorespiratory fitness, would decrease stress and increase mental resources.

\section{MATERIAL AND METHODS}

\section{Subjects}

The study group comprised 371 employees, who were recruited from small and medium-sized companies in Southern Finland. The local entrepreneur associations and occupational health care centers helped with the recruitment process. The inclusion criteria were: healthy defined as no permanent medication; aged 20-60 (mean age, women: 44 years, men: 42 years); no contraindications against walking exercise (Table 1). The participants were divided into exercise and control groups, so that approximately $10 \%$ of the participants would comprise the control group. The controls were from the same companies as the intervention participants, but they came from a different department, which separated them from the intervention. The participants of the control group were selected so that there would be approximately as many men as women and an even difference in skilled and unskilled workers. They were similar age as the exercise group and their leisure time physical activity (LTPA) at baseline did not differ from that of the exercise group.

The exercise group consisted of 338 participants (85 unskilled and 253 skilled workers; 212 women and 126 men) and the control group of 33 participants (19 unskilled and 14 skilled workers; 17 women and 16 men). Unskilled work was kitchen-, cleaning- and construction work. Skilled work was teaching-, journalism-, bank and insurance work. No differences were reported in the level of education between the exercise group and the control 
Table 1. Subject characteristics of the exercise intervention group and the control group

\begin{tabular}{lccc}
\hline \multicolumn{1}{c}{ Variable } & $\begin{array}{c}\text { Exercise group } \\
(\mathrm{N}=338)\end{array}$ & $\begin{array}{c}\text { Control group } \\
(\mathrm{N}=33)\end{array}$ & $\mathrm{p}$ \\
\hline Women/men $(\mathrm{n})$ & $212 / 126$ & $17 / 16$ & \\
Age $($ year $)(\mathrm{M} \pm \mathrm{SD})$ & $45.0 \pm 8.8$ & $41.0 \pm 6.9$ & 0.357 \\
Weight $(\mathrm{kg})(\mathrm{M} \pm \mathrm{SD})$ & $76.0 \pm 15.3$ & $81.0 \pm 12.6$ & 0.104 \\
Height $(\mathrm{cm})(\mathrm{M} \pm \mathrm{SD})$ & $170.0 \pm 8.7$ & $169.0 \pm 8.3$ & 0.403 \\
Body mass index $(\mathrm{M} \pm \mathrm{SD})$ & $26.1 \pm 4.4$ & $27.4 \pm 4.0$ & 0.693 \\
MET/h/week $(\mathrm{M} \pm \mathrm{SD})$ & $8.2 \pm 8.7$ & $7.7 \pm 11.5$ & 0.398 \\
Use of alcohol (doses/week) $(\mathrm{M} \pm \mathrm{SD})$ & $7.7 \pm 10.5$ & $8.7 \pm 11.0$ & 0.565 \\
Current smoker $(\%)$ & 21.0 & 12.0 & 0.816 \\
Level of education $(\%)$ & & & 0.171 \\
low & 38.0 & 50.0 & \\
moderate & 40.0 & 20.0 & \\
high & 22.0 & 30.0 & \\
\hline
\end{tabular}

$\mathrm{M}$ - mean; SD - standard deviation.

MET - metabolic equivalent.

group. The mean distance to work was $13.4 \mathrm{~km}$ and majority of the participants used their cars (83\%). Only $17 \%$ of the participants walked or cycled to work.

During the study, number of the participants included in the measurements in exercise group was: at the baseline, 338 participants; at 4-months, $\mathrm{N}=276(82 \%)$; at 8-months, $\mathrm{N}=306$ (91\%); at 12-months, $\mathrm{N}=306$ (91\%); and at 24-months, $\mathrm{N}=178$ (53\%). Participation in the measurements of the control group was: at the baseline, $\mathrm{N}=33$; at 4-months, $\mathrm{N}=29(88 \%)$; at 8-months, $\mathrm{N}=27$ (82\%); at 12-months, $\mathrm{N}=28(85 \%)$; and at 24-months, $\mathrm{N}=28(85 \%)$. The study protocol was approved by the Ethical Committee of the Pirkanmaa Hospital District.

\section{Study design}

The exercise group underwent a 12-month exercise program, which contained 2-days training camps at the Sport Institute of Finland, at baseline, 4-, 8-, 12- and 24-months. The training camps contained measurements (weight, height, fat percentage, bicycle ergometer test, muscleand flexibility tests and questionnaires). The participants were supervised and exercised in a group. They took part in lessons about health related issues, such as physical fitness and muscle care. The persons in the exercise group formed groups of 15-20 persons within the same company and each group had a coach (a physiotherapist or an exercise instructor). During the whole intervention, the same coach guided the particular group.

Between training camps, the exercise program contained one to 2 supervised exercise sessions in a group per month and 3-5 unsupervised exercise sessions per week (mainly by walking, skiing and biking). Every participant had an individualized exercise program based on the estimated oxygen uptake $\left(\mathrm{VO}_{2 \max }\right)$. During the exercise, the mean heart rate was mainly at the moderate level, mainly $60-80 \%$ of the participant's estimated maximal heart rate. Exercise intensity was monitored with Polar heart rate microcomputers (Polar Electro, Kempele, Finland). The exercises amount and intensity between training camps were recorded with personal, web-based, exercise diaries. The coach viewed the content of the exercise diary twice-a-month, and if needed gave more 
specific information concerning the exercise programs for the following weeks. After a 12-month supervised exercise program, there was a 12-month follow-up without exercise coaching. This evaluated the possible stability of the results observed during the intervention. The control group had no supervised exercise or program, but both the intervention and the control group participated in all the measurements during the same time points (baseline, 4-, 8-, 12-, and 24-month).

\section{Life style questionnaire}

Information on the use of alcohol and tobacco products, and leisure time physical activity habits was obtained at the baseline and after 12 months by the use of a questionnaire. Exercise amount and intensity between training camps were also evaluated with personal exercise diaries using the Internet. At baseline, 23\% of the exercise group were current smokers and there were no changes in smoking or alcohol use habits during the intervention (Table 1). The weekly leisure time physical activity (LTPA) was determined using 3 questions concerning frequency, duration and intensity of the exercise [23]. The LTPA was determined from responses to a single question with 10 categories: (A) less physical activity than once a month or not at all; (B) at least once a month, but less than once a week; (C) once a week; (D) 2 times a week; (E) 3 times a week; (F) 4 times a week; $(\mathrm{G}) 5$ times a week; (H) 6 times a week; (I) 7 times a week; (J) at least 7 times a week, how many? The duration of each PA session was established by asking a single question with 8 categories: (A) at most $10 \mathrm{~min},(\mathrm{~B})$ 11-20 min, (C) 21-30 min, (D) 31-40 min, (E) 41-50 min, (F) 51-80 min, (G) 81-90 min, (H) more than $90 \mathrm{~min}$. Information on the intensity of the PA was obtained by asking a single question - My PA intensity is average: (A) walking, (B) light jogging, (C) running, (D) high speed running.

According to the answers, we calculated the metabolic equivalent (MET) h/week values (LTPA times per week $\times$ duration $\times$ intensity) (Table 1$)$. One MET represents the approximate rate of $\mathrm{VO}_{2}$ consumption of a seated individual at rest, which is $3.5 \mathrm{ml} \mathrm{O} / 2 \mathrm{~kg} / \mathrm{min}[24,25]$.

\section{Cardiorespiratory fitness $\left(\mathrm{VO}_{2 \max }\right)$}

Maximal oxygen uptake was extrapolated indirectly on the basis of an electrically braked bicycle ergometer (Ergoline 800S, Ergoline, Berlin, Germany) test (pedal rate of $60 \mathrm{rpm}$ ) using 3 submaximal loads. The lowest submaximal load was calculated to produce a heart rate of approximately 120 beats per minute and the highest submaximal load approximately $85 \%$ of age-adjusted maximal heart rate. The age-adjusted maximal heart rate was derived from the established reference values [26], and maximal oxygen uptake was extrapolated from the maximal heart rate. The same individual workloads that were used at the baseline test were used during the follow-up tests. In the case of lower heart rates at the highest load, the additional 4th work load was used to increase the heart rate to the expected level.

\section{Stress symptom index}

Occupational Stress Questionnaire (OSQ) is a widely used method in occupational health to assess characteristics and stress factors of work and stress reactions of employees in Finnish companies [27]. The Questionnaire has been investigated in several research projects of the Finnish Institute of Occupational Health since 1977 [27,28]. The validity of the stress question of OSQ has been studied and there is an association between psychological symptoms and mental resources [29]. The Stress Symptom Index (SSI) was calculated using sum scales from the questions measuring stress and satisfaction with work and life. It is allowed to calculate sum scores within a specific theme of OSQ [27].

The SSI was calculated from 4 questions with 5 categories [29]:

A. Stress was the situation when a person feels tense, restless, nervous, anxious or is unable to sleep at night 
because his/her mind is troubled all the time. Do you feel that kind of stress these days? Answers (Likertscale: $1-5$ points): (1) not at all, (2) only a little, (3) to some extent, (4) rather much, (5) very much.

B. What is your health state compared to that of other people of your age? Answers (Likert-scale: 1-5 points): (1) very good, (2) rather good, (3) average, (4) rather poor, (5) very poor.

C. How satisfied are you with your present work? Answers (Likert-scale: 1-5 points): (1) very satisfied, (2) rather satisfied, (3) neither satisfied nor dissatisfied, (4) rather dissatisfied, (5) very dissatisfied.

D. How satisfied are you with your present life? Answers (Likert-scale: 1-5 points): (1) very satisfied, (2) rather satisfied, (3) neither satisfied nor dissatisfied, (4) rather dissatisfied, (5) very dissatisfied.

The higher the SSI sum scale, the higher the stress level and the lower the SSI sum scale, the lower the stress level. At the baseline, for the purpose of analyses the participants were categorized into 4 subgroups according to their stress symptoms.

\section{Mental resource index}

Mental resource index (MRI) was calculated using sum scale from 3 questions with 5 categories [29]:

A. Have you been active and energetic lately? Answers (Likert-scale: 1-5 points): (1) constantly, (2) rather often, (3) now and then, (4) rather seldom, (5) not at all.

B. Do you feel yourself capable and confident? Answers (Likert-scale: 1-5 points): (1) constantly, (2) rather often, (3) now and then, (4) rather seldom, (5) never.

C. Do you think you have done your daily tasks well lately? Answers (Likert-scale: 1-5 points): (1) constantly, (2) rather often, (3) now and then, (4) rather seldom, (5) not at all.

Low MRI sum scale means high mental resources, and high MRI sum scale means low mental resources. The MRI has been used earlier [27]. For the purpose of analyses, at the baseline the participants were categorized into 3 subgroups according to their mental resources.

\section{STATISTIC}

Statistical analyses were run by SPSS (Statistical Package for Social Sciences, version 19.0) software. The normality of the variables was tested and in the case of abnormal distributions logarithm transformations were applied. After the test of normality, repeated measures ANOVA was 1st performed for the intervention and control groups. Trial× group (intervention/control) interaction in repeated measures ANOVA was used separately for the intervention (0-month/4-months/8-months/12-months) and the follow-up (0-month/24-months) samples. In the case of significant ANOVA, age, gender and BMI were used as covariates (ANCOVA). A paired t-test using Bonferroni's correction within the intervention or control group was done as a post-hoc test. Similarly, the difference between subgroups was analysed by ANOVA and ANCOVA followed by a paired t-test using Bonferroni's correction as a post-hoc test. Correlations were calculated with Pearson's correlation. There were no statistically significant differences in the results between the genders or skilled/ unskilled workers, therefore, the results are presented combined.

\section{RESULTS}

\section{Stress symptom index}

The stress symptom index (SSI) decreased by $16 \%$ $(\mathrm{p}<0.0001)$ in the exercise group, but no change was observed in the control group (ANCOVA, trial $\times$ group interaction using age, sex and BMI as covariates during intervention, $p=0.001$ and between baseline vs. 24 months, $\mathrm{p}=0.004)$. In the exercise group, the SSI decreased during the exercise program by $10 \%$ ( $p<0.0001)$ after 4 months, by $15 \%$ ( $p<0.0001)$ after 8 months, and by $16 \%$ ( $p<0.0001)$ after 12 months. After the 12-month follow-up, SSI were still decreased by $13 \%$ ( $p<0.0001)$ 
compared to the baseline (Table 2). In the control group there was no positive change in SSI during the intervention or the follow-up.

The subgroup having the most stress symptoms at baseline - the SSI subgroup 4 (sum points: $18-30, \mathrm{~N}=59$ ), decreased their SSI most during the intervention (ANOVA for subgroups, $\mathrm{p}<0.0001$ ), i.e.: by $14 \%$ ( $\mathrm{p}<0.0001$ ) after 4 months, by $22 \%$ ( $p<0.0001)$ after 8 months, and by $26 \%$ ( $p<0.0001$ ) after 12 months. After the 12-month follow-up, totalling 24 months, SSI was still decreased by $21 \%$ ( $p<0.0001$ ) compared to the baseline. During the intervention, the SSI subgroup 3 (sum points: 15-17, $\mathrm{N}=104)$ decreased their SSI by $16 \%$ ( $\mathrm{p}<0.0001)$ after 4 months, by $20 \%$ ( $p<0.0001)$ after 8 months, and by $18 \%$ ( $p<0.0001)$ after 12 months.

After the 12-month follow-up, SSI was decreased by $13 \%$ ( $p<0.0001)$ compared to the baseline. The SSI subgroup 2 (sum points: $12-14, \mathrm{~N}=103$ ) decreased their SSI by $7 \%$ (p < 0.0001) after 4 months, by $13 \%$ (p < 0.0001) after 8 months, by $14 \%$ ( $p<0.0001)$ after 12 months and after the 12-month follow-up, SSI remained decreased by $8 \%$ ( $p=0.045)$. The SSI subgroup 1 (sum points: $6-11$, $\mathrm{N}=72$ ), with the lowest stress symptoms at baseline, had no changes in SSI during the intervention or the followup (Figure 1). The change in stress symptoms between the exercise group and the control group during intervention (baseline vs. 12-month) was $\mathrm{p}<0.0001$ and after the follow-up (baseline vs. 24-month) it was $p=0.004$.

\section{Mental resources}

The mental resource increased by $8 \%$ in the exercise group, while no significant changes occurred in the control group (ANCOVA during intervention, $p=0.001$, and between baseline and 24 months, $p=0.008)$. Among the exercise group, MRI increased by $5 \%(p=0.015)$ after 4 months, by $8 \%$ ( $p=0.001)$ after 8 months, and by $8 \%$ ( $p<0.0001)$ after 12 months. After the follow-up at 24 months, MRI was still increased by $5 \%(\mathrm{p}=0.031)$

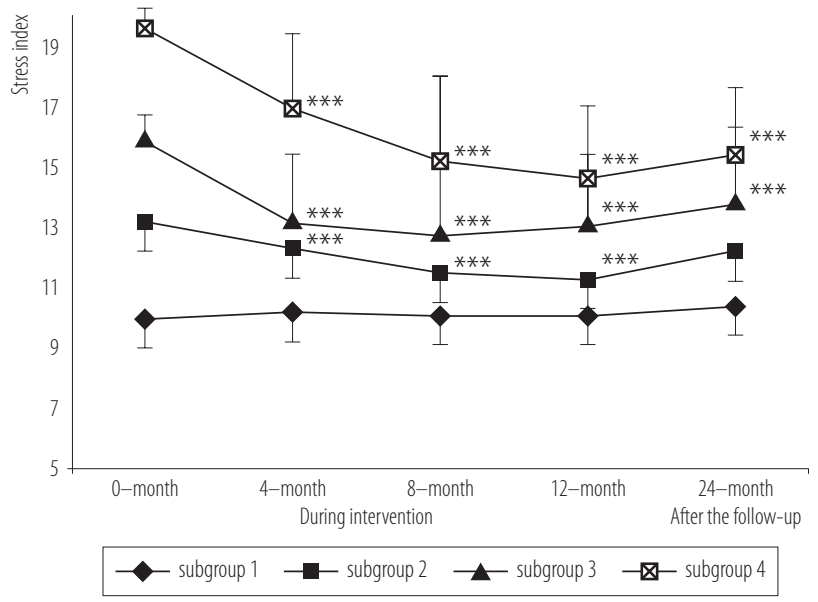

$* * * \mathrm{p}<0.001$.

At baseline, the participants were categorized into 4 subgroups according to their stress symptoms: subgroup 1 had 6-11 sum points, subgroup 2 had 12-14 sum points, subgroup 3 had 15-17 sum points and subgroup 4 had 18-30 sum points at the baseline.

Fig. 1. Stress symptoms according to the subgroups during the exercise intervention and follow-up (24-month)

compared to the baseline (Table 2). In the control group, there was no positive change in MRI during the intervention or follow-up (Table 2).

The mental resource index subgroup 3 (sum points: 7-15, $\mathrm{N}=117$ ), having the lowest mental resources at baseline, increased their MRI by $12 \%$ ( $p<0.0001$ ) after 4 months, by $16 \%(\mathrm{p}<0.0001)$ after 8 months, and by $18 \%$ ( $p<0.0001)$ after 12 months. After the 12-month follow-up, MRI remained increased by $18 \%$ ( $\mathrm{p}<0.0001$ ) compared to the baseline. The MRI subgroup 2 (sum points $6, \mathrm{~N}=126)$ increased their MRI by $6 \%(\mathrm{p}=0.021)$ after 12 months, but after the follow-up the MRI was at the same level as it was at the baseline (Figure 2).

\section{Cardiorespiratory fitness (CRF)}

The cardiorespiratory fitness improved by $7 \%$ in the exercise group during the intervention. No significant changes occurred in the control group (ANCOVA during intervention, $\mathrm{p}<0.0001$, and between baseline vs. follow-up, $\mathrm{p}=0.015)$. The CRF improved in the exercise group 


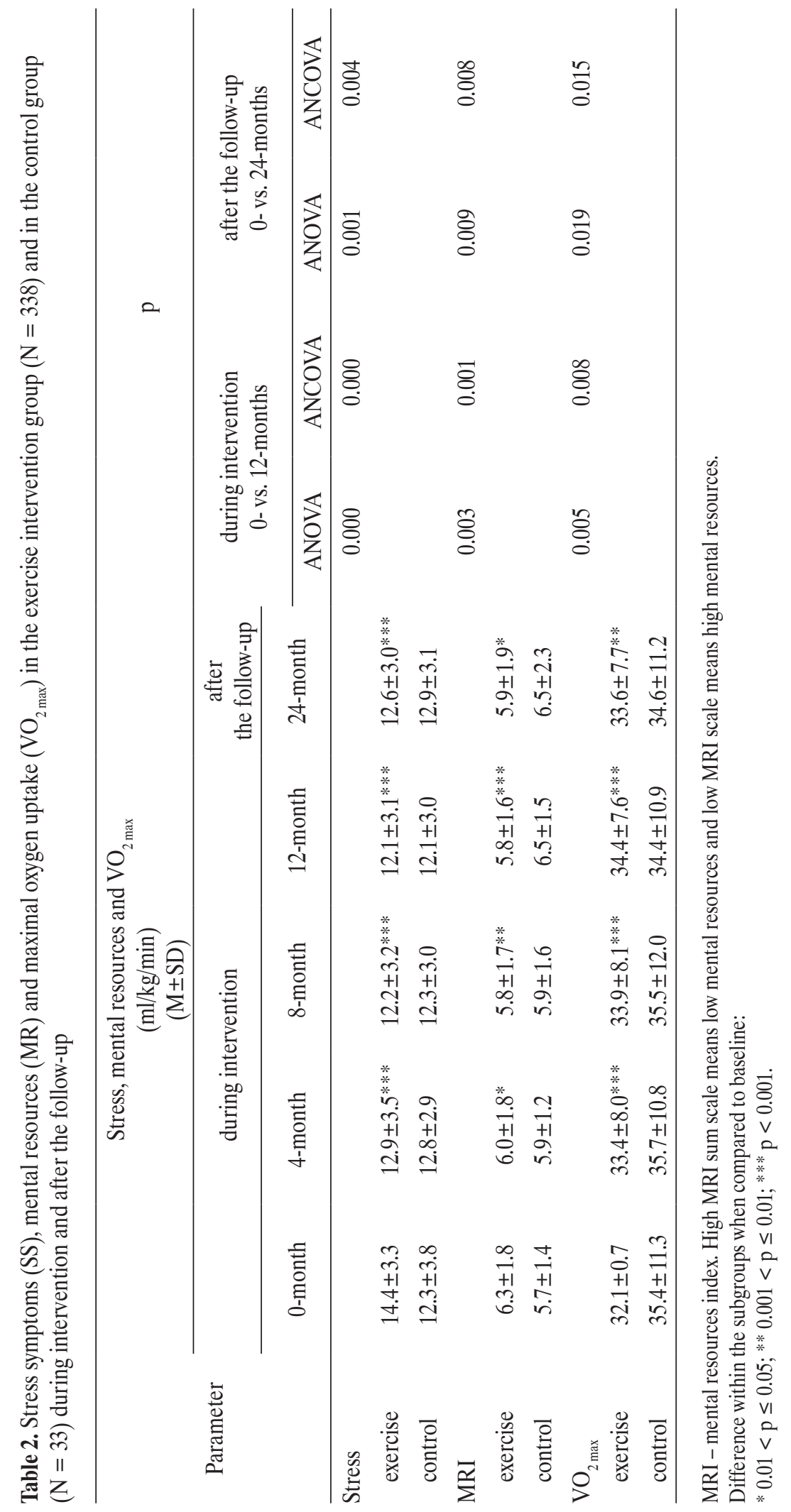




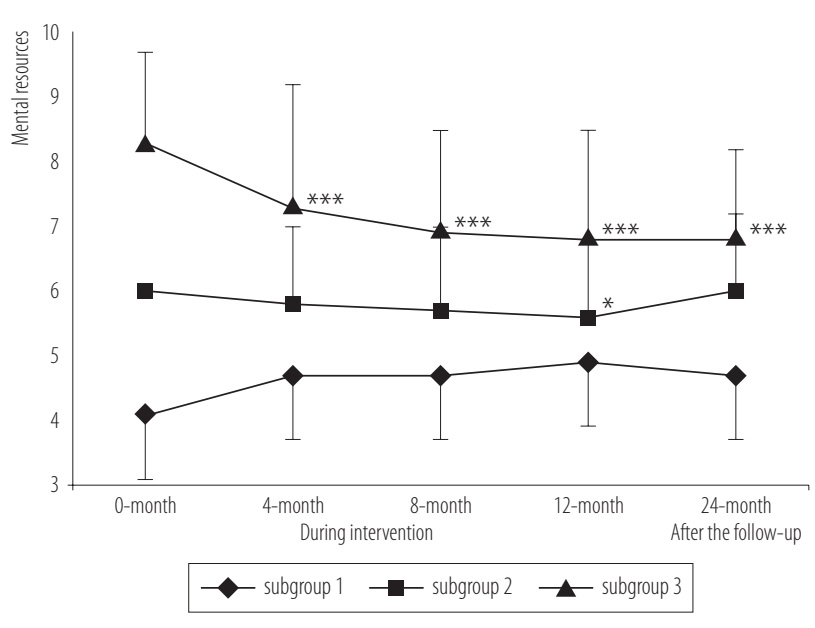

$* \mathrm{p}<0.01$.

Fig. 2. Mental resources according to the subgroups during the exercise intervention and follow-up

after 4 months by $4 \%(\mathrm{p}<0.0001)$, after 8 months by $6 \%$ $(\mathrm{p}<0.0001)$ and after 12 months by $7 \%(\mathrm{p}<0.0001)$, and baseline vs. follow-up by $5 \%$ ( $<<0.0001)$ (Table 2). During the intervention, the CRF did not change in the control group ( $p=0.396$, statistically insignificant) or during the follow-up ( $p=0.786$, statistically insignificant). There was a significant negative correlation between change in SSI and change in $\mathrm{VO}_{2 \text { max }}(\mathrm{ml} / \mathrm{kg} / \mathrm{min})(\mathrm{r}=-0.19$, $\mathrm{p}<0.01)$. The change in MRI did not correlate with the change in CRF ( $r=-0.064, p=0.28)$. The change in cardiorespiratory fitness between exercise group and control group during the intervention (baseline vs. 12-month) was $p=0.007$ and after the follow-up (baseline vs. 24-month) it was $p=0.040$.

\section{Leisure time physical activity (LTPA)}

According to the internet-based exercise diaries, the mean LTPA during the active year was $19.5( \pm 11.0) \mathrm{MET} / \mathrm{h} /$ week (h/week) and during the follow-up year, $15.7( \pm 12.3) \mathrm{MET} / \mathrm{h} /$ week. According to the questionnaire, the exercise group increased their selfreported leisure time physical activity (LTPA), during the intervention, by $71 \%(\mathrm{p}=0.016)$. The mean $(\mathrm{SD})$ of LTPA increased from $8.3( \pm 8.8) \mathrm{MET} / \mathrm{h} /$ week at baseline to 13.7 $( \pm 45.2) \mathrm{MET} / \mathrm{h} /$ week at 12 -month in the exercise group, but the increase of LTPA did not correlate with the change in SSI ( $\mathrm{r}=0.05, \mathrm{p}=0.33)$. 12-month LTPA of self-reported questionnaires correlated with the LTPA of exercise diaries $(r=0.200, p=0.0001)$. The mean (SD) of LTPA of the control group was at baseline $7.7( \pm 10.1) \mathrm{MET} / \mathrm{h} /$ week, and at 12 months, it was $7.9( \pm 10.9) \mathrm{MET} / \mathrm{h} /$ week.

\section{DISCUSSION}

The present study demonstrated that a 12-month physical exercise intervention had a clear impact on the wellbeing of the working adults. Stress symptoms of the exercise group decreased and mental resources, leisure time physical activity as well as cardiorespiratory fitness improved during the 12-month intervention, and these positive changes remained after the follow-up year. The improvements were the greatest among the persons who at the baseline had the most stress symptoms and the least mental resources.

Leisure-time physical activity increased and cardiorespiratory fitness of the exercise group improved, gradually, during the 12-month intervention. The decrease in stress symptoms was associated with the improvement in measured CRF, but not with the increase in self-reported LTPA. However, the improvement of CRF did not correlate with the improvement in mental resources even if mental resources improved in the exercise group. In the previous study of Kettunen et al. [30] both physical fitness and volume of LTPA were related with low stress and high mental resources in a cross-sectional study of Finnish young men $(\mathrm{N}=831)$. Our results differ from the earlier studies reporting that physical activity, itself, rather than improvement in cardiorespiratory fitness, seems to be effective in improving mental well-being, especially mental health symptoms and mood [31,19] in employees [5] and the general population $[4,11,17]$. Our results show that regular physical exercise is important to mental well-being as long as it improves 
fitness, regardless of the quality or duration of PA. The differences between the present study and some earlier studies might be, at least partly, caused by the different study design (intervention vs. population sample) as well as differences in measuring mental well-being and CRF.

In our study, improvement in CRF was associated with the decreased stress symptoms. According to a meta-analysis of 73 studies by Jackson and Dishman [32], good CRF helps recovery from stress. Good CRF was also associated with psychological resources in a community sample [33]. The results are in accordance with the stress-buffering hypothesis of exercise against stress [33,34]. The idea is that good physical condition or improved fitness are likely to facilitate the individual's ability to deal with stress [4].

We investigated both self-reported LTPA (questionnaire and exercise diary) and measured CRF several times during the study instead of assessing either LTPA or CRF once during the study. This is a major strength of our study. In a critical review of the effectiveness of worksite physical activity programs on physical activity, physical fitness and health, Proper et al. [35] have underlined the importance of implementation of worksite physical activity programs to increase the level of physical activity. Our study supports this idea. Promoting and measuring cardiorespiratory fitness can motivate employees to adopt a more physically active lifestyle and strengthen their mental resources, and ability to cope with stress.

There were significant differences in changes in stress symptoms, mental resources and cardiorespiratory fitness between the exercise and control groups, during the intervention period and after the follow-up year. It cannot be ruled out, that additional factors could have improved the work environment and affected well-being of the participants, but it is very improbable that other confounding factors occurred simultaneously at many different companies. According to the questionnaires, the participants increased their LTPA by $71 \%$ during the intervention. Both individual exercise program and supervised exercise sessions were planned to contain enough aerobic physical activity, which could lead to the increased cardiorespiratory fitness and would, therefore, improve coping with stress.

The current study has limitations. Because the participants were recruited from the real-time, working life, we decided not to use randomization or matched pair controls, and allocated approximately $10 \%$ of the participants to the control group. Therefore, the size of the control group was clearly lower than that of the exercise intervention group. Also, the number of drop-outs was somewhat higher during the follow-up, although the drop-out rate was low during the 12-month intervention. In addition, there is a lack of precise definition of psychological well-being, which causes difficulties in comparison between the studies using different estimates of mental well-being [36,37]. However, our results were validated by the questions of OSQ.

Based on the current results, interventions in the workplace that improve CRF could be suggested as a preventive method for maintaining and improving mental well-being of employees. Interventions may have long-term effects for keeping people in working life [38]. Moreover, if interventions lead to changes in lifestyle, we expect long-term effects on individual's health [39]. Poor mental well-being and elevated level of stress may cause sick leaves among workers and increase health-related costs of companies. Therefore, employers should be interested in paying more attention to actions that may increase mental resources and decrease stress symptoms of their employees. There is a growing evidence to support the idea that workplace well-being interventions may improve economical results of the company [40].

\section{CONCLUSIONS}

The 12-month physical exercise intervention has decreased stress symptoms and improved mental resources among healthy working adults. This improvement was associated with the heightened measured cardiorespiratory fitness. The positive changes have remained after the 12-month 
follow-up. Importantly, the participants having the highest stress symptoms and the lowest mental resources, benefitted from the intervention the most. This indicates that a high level of stress symptoms and a low level of mental resources can be used as selection criterion for exercise interventions in the workplace.

\section{REFERENCES}

1. Netz Y, Wu MJ, Becker BJ, Tenenbaum G. Physical activity and psychological wellbeing in advanced age: A meta-regression analysis of intervention studies. Psychol Aging. 2005;20: 272-84, http://dx.doi.org/10.1037/0882-7974.20.2.272.

2. Schnohr P, Kristensen TS, Prescott E, Scharling H. Stress and life dissatisfaction are inversely associated with jogging and other types of physical activity in leisure time - The Copenhagen City Hearth Study. Scand J Med Sci Sports. 2005;15(2): 107-12, http://dx.doi.org/10.1111/j.1600-0838.2004.00394.x.

3. Weyerer S, Kupfer B. Physical exercise and psychological health. Sports Med. 1994;17:108-16, http://dx.doi.org/ 10.2165/00007256-199417020-00003.

4. Scully D, Kremer J, Meade MM, Graham R, Dudgeon K. Physical exercise and psychological wellbeing: A critical review. Br J Sports Med. 1998;32:111-20, http://dx.doi.org/ 10.1136/bjsm.32.2.111.

5. Taylor AH. Physical activity, anxiety and stress. In: Biddle SHJ, Fox KR, Boutcher SH, editors. Physical activity and psychological well-being. London: Routledge; 2000. p. 10-14.

6. Aldana SG, Sutton LD, Jacobson BH, Quirk MG. Relationships between leisure time, physical activity, and perceived stress. Percept Mot Skills. 1996;3:251-60.

7. Steptoe A, Krarsley N, Walters N. Cardiovascular activity during mental stress following vigorous exercise in sportsmen and inactive men. Psychophysiology. 1993;30(3):245-52, http://dx.doi.org/10.1111/j.1469-8986.1993.tb03350.x.

8. Fukukawa Y, Nakashim C, Tsuboi S, Kozakai R, Doyo W, Niino W, et al. Age differences in the effect of physical activity on depressive symptoms. Psychol Aging. 2004;19(2): 346-51, http://dx.doi.org/10.1037/0882-7974.19.2.346.
9. Allgöwer A, Wardle J, Steptoe A. Depressive symptoms, social support and personal health behaviours in young men and women. Health Psychol. 2001;20(3):223-7, http://dx.doi. org/10.1037/0278-6133.20.3.223.

10. Lane AM, Lovejoy DJ. The effects of exercise on mood changes: The moderating effect of depressed mood. J Sports Med Phys Fitness. 2001;41:239-45.

11. Hassmen P, Koivula N, Uutela A. Physical exercise and psychological well-being. A population study in Finland. Prev Med. 2000;30(1):17-25, http://dx.doi.org/10.1006/pmed. 1999.0597.

12. Lampinen P, Heikkinen RL, Ruoppila I. Changes in intensity of physical exercise as predictors of depressive symptoms among older adults: An 8 year follow up. Prev Med. 2000;30(5):371-80, http://dx.doi.org/10.1006/pmed.20 00.0641 .

13. Pohjonen T, Ranta R. Effects of worksite physical exercise intervention on physical fitness, perceived health status, and work ability among home care workers: Five-year followup. Prev Med. 2001;32(6):465-75, http://dx.doi.org/10.1006/ pmed.2001.0837.

14. Chida Y, Steptoe A. Positive psychological well-being and mortality: A quantitative review of prospective observational studies. Psychos Med. 2008;70(7):741-56, http://dx.doi. org/10.1097/PSY.0b013e31818105ba.

15. Ortega FB, Lee D-C, Sui X, Kubzansky L, Ruiz J, Baruth $\mathrm{M}$, et al. Psychological well-being, cardiorespiratory fitness, and long-term survival. Am J Prev Med. 2010; 39(5):440-8, http://dx.doi.org/10.1016/j.amepre.2010.07.015.

16. Lindwall M, Ljung T, Hadzibajramovic E, Johansdottir IH. Self-reported physical activity and aerobic fitness are differently related to mental health. Ment Health Phys Act. 2012;5(1):28-34, http://dx.doi.org/10.1016/j.mhpa. 2011.12.003.

17. Thøgersen-Ntoumani C, Fox KR. Physical activity and mental well-being typologies in corporate employees: A mixed methods approach. Work Stress. 2005;19(1):50-67, http:// dx.doi.org/10.1080/02678370500084409. 
18. Gabriel P, Liimatainen MR. Mental health in the workplace. Geneva: International Labour Office; 2000.

19. Cox T, Leka S, Ivanov I, Kortum E. Work, employment and mental health in Europe. Work Stress. 2004;18(2):179-85, http://dx.doi.org/10.1080/02678370412331272651.

20. Sonnentag S. Work, recovery activities, and individual wellbeing: A diary study. J Occup Health Psychol. 2001;6(3): 196-210, http://dx.doi.org/10.1037/1076-8998.6.3.196.

21. Sonnentag S, Natter E. Flight attendants' daily recovery from work: Is there no place like home? Int J Stress Manag. 2004;11(4):366-91, http://dx.doi.org/10.1037/1072-5245. 11.4.366.

22. Hobfoll SE. Stress, culture, and community: The psychology and physiology of stress. New York: Plenum; 1998.

23. Vasankari TJ, Kujala U, Vasankari T, Ahotupa M. Reduced oxidized LDL levels after a ten-month exercise training program. Med Sci Sports Exerc. 1998;30(10):1496-501, http:// dx.doi.org/10.1097/00005768-199810000-00005.

24. American College of Sports Medicine (ACSM). Guidelines for exercise testing and prescription. 6th ed. Philadelphia: Lippincott Williams \& Wilkins; 2000.

25. Sjögren T, Nissinen KJ, Järvenpää SK, Ojanen MT, Vanharanta H, Mälkiä EA. Effects of physical exercise intervention on subjective physical well-being, psychosocial functioning and general well-being among office workers: A cluster randomized-controlled cross-over design. Scand J Med Sci Sports. 2006;16(6):381-90, http://dx.doi.org/10.1111/j.16000838.2005.00516.x.

26. Seliger V, Bartunek Z. Mean values of indices of physical fitness in the investigation of Czechoslovak population aged 12-55 years. Praha: CSTV; 1976.

27. Elo A-L, Leppänen A, Lindström K, Ropponen T. OSQ, Occupational Stress Questionnaire - Users instructions. Reviews 19. Helsinki: Finnish Institute of Occupational Health; 1992.

28. Elo A-L, Leppänen A, Sillanpää P. Applicability of survey feedback for an occupational health method in stress management. Occup Med. 1998;48(3):181-8, http://dx.doi. org/10.1093/occmed/48.3.181.
29. Elo A-L, Leppänen A, Jahkola A. Validity of a singleitem measure of stress symptoms. Scand J Work Environ Health. 2003;29(6):444-51, http://dx.doi.org/10.5271/ sjweh.752.

30. Kettunen O, Kyröläinen H, Santtila M, Vasankari T. Physical fitness and volume of leisure time physical activity relate with low stress and high mental resources in young men. J Sports Med Phys Fitness. 2014;54(4):545-51.

31. Pohjonen T, Ranta R. Effects of worksite physical exercise intervention on physical fitness, perceived health status, and work ability among home care workers: Five-year followup. Prev Med. 2001;32(6):465-75, http://dx.doi.org/10.1006/ pmed.2001.0837.

32. Jackson E, Dishman R. Cardiorespiratory fitness and laboratory stress: A meta regression analysis. Psychophysiology. 2006;43(1):57-72, http://dx.doi.org/10.1111/j.1469-8986. 2006.00373.x.

33. Ensel WM, Lin N. Physical fitness and stress process. J Comm Psychol. 2004;32(1):81-101, http://dx.doi.org/ 10.1002/jcop.10079.

34. Gerber M, Pühse U. Do exercise and fitness protect against stress-induced health complaints? A review of the literature. Scand J Public Health. 2009;37(8):801-19, http://dx.doi. org $/ 10.1177 / 1403494809350522$.

35. Proper K, Koning M, van der Beek A, Hildebrandt V, Bosscher R, van Mechelen W. The effectiveness of worksite physical activity programs on physical activity, physical fitness, and health. Clin J Sports Med. 2003;13(2):106-17, http://dx.doi.org/10.1097/00042752-200303000-00008.

36. Roscoe LJ. Wellness: A review of theory and measurement for counselors. J Couns Dev. 2009;87(2):216-26, http:// dx.doi.org/10.1002/j.1556-6678.2009.tb00570.x.

37. Milles L. Physical activity and health. Nutr Bull. 2007;32(4):314-63, http://dx.doi.org/10.1111/j.1467-3010. 2007.00668.x.

38. Eriksen HR, Ihlebæk C, Mikkelsen A, Grønninggsæter H, Sandal GM, Ursin H. Improving subjective health at the worksite: A randomized controlled trial of stress 
management training, physical exercise and an integrated health programme. Occup Med. 2002;52(7):383-91, http:// dx.doi.org/10.1093/occmed/52.7.383.

39. Bouchard C, Shephard RJ, Stephens T. Physical activity fitness and health consensus statement. Champaign (IL): Human Kinetics Publishers; 1993.
40. Cooper C, Dewe P. Well-being-absenteeism, presenteeism, costs and challenges. Occup Med. 2008;58(8):522-4, http:// dx.doi.org/10.1093/occmed/kqn124.

This work is available in Open Access model and licensed under a Creative Commons Attribution-NonCommercial 3.0 Poland License - http://creativecommons.org/ licenses/by-nc/3.0/pl/deed.en. 